\title{
Leveraging Current Knowledge and Exploring Future Potential of Biochar
}

\author{
Netra B Chhetri* \\ Arizona State University, USA
}

Submission: March 18, 2020; Published: March 30, 2020

*Corresponding author: Netra B Chhetri, School for the Future of Innovation in Society, Arizona State University, Tempe, AZ 85287-5603, USA

Keywords: Biochar; Organic waste; Chemical changes; Fertilizer; Sustainable agriculture; Sustainable development

\section{Introduction}

Among the biggest challenges of the $21^{\text {st }}$ century is the need to nearly double food production by 2050, reduce persistent energy poverty while reducing the emissions of greenhouse gases in the atmosphere, and build resilience to changing climate [1]. The strong needs to focus on solving these challenges have sparked a global interest in large-scale production and use of biochar [2]. Created by burning organic waste, typically between 300$700^{\circ} \mathrm{C}$ in oxygen-deprived chambers, biochar is a carbon-rich form of charcoal that has a number of uses [3]. If incorporated in soil, it enhances soil's ability to retain nutrients, reduces runoff chemicals from agricultural land, improves water-holding capacity of soils and lowers $\mathrm{CH}_{4}$ and $\mathrm{N}_{2} \mathrm{O}$ emissions from land [4]. The value of biochar can be increased significantly through additional mechanical and engineering processes, whereby it can be converted into high quality charcoal substituting firewood as a source of household energy, a primary driver of deforestation in many parts of the world. Additionally, biochar is estimated to offset global anthropogenic greenhouse gas emissions by a full 12 percent $\mathrm{CO}_{2}$-e (1.8GT CO $\left.2 \mathrm{yr}^{-1}\right)$ without endangering food security, habitat or ecosystem services [5]. The field of biochar is fastmoving and provides a uniquely powerful case for pathways to meet multiple UN Sustainable Development Goals (SDGs).

\section{Food Security and Agro-ecology}

The demand for food is growing, but the resources required to generate them are limited and, in many cases, dwindling [6]. The potential contribution of biochar to food production has been widely reported and field studies of biochar have examined its effects on soil fertility through chemical changes, interactions with soil when combined with fertilizers, and the effects on the plants themselves. Seven field trials conducted in the UK found a significant positive effect for all biochar treatments and an increase in average crop yields of $0.4 \mathrm{t} / \mathrm{ha}$ [7]. In addition to greater yields, biochar-amended soil provided better yield predictability, reduced germination time, better drought resilience, and reduced reliance on fertilizer. In a meta-analysis of 86 different biochar treatments on a range of soil and crop types, Verheijen et al. [8] reported that, compared with non-amended soils, some biocharamended soils were less productive $(-45 \%)$ and some were much more productive $(+95 \%)$ with a grand mean of $+10 \%$. The greatest (positive) effects of biochar were observed in soils that were acidic to neutral and relatively coarse in texture.

The emerging body of literature indicates that there is substantial potential for biochar application to improve crop yields. A number of benefits have been reported for biochar application to soils including greater yields, better predictability of yields, reduced germination time, extension of cropping season, and greater resilience to drought [9]. For smallholder farmers, to whom soil fertility and water availability are seen as key constraints to better crop production, biochar based strategies have the potential to offer pathways to livelihoods and food security on a sustainable basis. Introduction of biochar in the smallholder setting can be a catalyst to sustainable agriculture and become the new global standard, not an outlier. Simultaneously, it can also lead to a greater understanding of the solutions to food, energy, and water challenges. However, not all crops respond to biochar the same way and not all soils show broad improvement with biochar application; even when the biochar appears fit for the purpose. Current knowledge about the effects of adding biochar to smallholder agricultural system is not sufficient to support large-scale production and use. If biochar has a neutral effect on certain types of agricultural practices, there may be no argument 
for its use. Local socioeconomic and environmental factors are critically important to understand the potential benefit of biochar application to smallholder settings.

\section{Contributions to Local Hydrology and Soil Health}

Soil - the medium that provides support and sustenance for crops - acts as a crucial nexus between food, energy and water. It is the medium where water, gas, microbes, plants and fauna intersect. Because biochar is a porous material that retains nutrients and water, and improves soil structure, its application as a soil amendment can alter soil properties and local hydrology, including agricultural soil-water-holding capacity and infiltration [10]. Uzoma et al. [11] compared the effect of biochar on sandy soils and found that it improved crop nutrient uptake and wateruse efficiency by $6 \%, 91 \%$, and $139 \%$ in plots amended with 10,15 , and 20 tonnes of biochar/ha, respectively. A study by Asai et al. [12] in northern Laos also found that higher rates of biochar application improved water percolation, which improved the overall water availability for plants. Other studies show that biochar positively affects soil fungal communities, which contributes to drought resistance. For example, in Australia, biochar and inoculated mineral fertilizers, increased mycorrhizal colonization in wheat [13]. Soil fungal communities have been shown to augment crop drought tolerance and water availability, and bolster yield [14].

The carbon locked in biomass is relatively quickly decomposed and reemitted to the atmosphere upon decay in soil, with longer times for woody biomass and colder climates. On average biochar retains 50 percent (range 10-70 percent) of the carbon present in the original biomass and slows down the rate of carbon decomposition by one or two orders of magnitude, that is, in the scale of centuries or millennia. It, therefore, has implications for soil carbon sequestration and carbon credit. By converting the carbon-neutral process of naturally decaying organic matter and turning it into carbon negative technology, biochar has drawn an impressive array of discussions to act on climate change. Impact of biochar application by location and over time can vary given the range of factors including:

a) Soil pH - most biochars have liming effect in acidic soils;

b) Nutrient availability - biochar is a soil conditioner, which improves soil functions by reducing nutrient loss, increasing bioavailability of nutrients, and decreasing nutrient leaching;

c) Soil moisture - due to its porous structure and large surface area, biochar can retain water and improve the overall water-holding capacity of soils; and

d) Soil organic matter - it's ability in increasing and sustaining organic matter content in soil is related to the soil type and the timescale and amount of biochar is applied.

\section{Energy and Climate Mitigation Potential}

Energy poverty, a phenomenon highly concentrated in leastdevelopment regions of the world, presents a significant barrier to achieving sustainable development goals of healthy and prosperous society. Through additional engineering processes, biochar can be converted into high quality charcoal, substituting for wood as a source of household energy, a primary driver of deforestation. The provision of clean energy through the production of green charcoal from biochar offers an opportunity to address energy poverty. Production of briquettes from biochar can bring benefits at many scales, particularly in energy-insecure areas. By building the knowledge and experience necessary for improved performance green charcoal from biochar, our project focuses on developing a mechanism for distributive energy access while also driving energy innovation toward "low-and zerocarbon" energy portfolio. Production of biochar and the broader innovation ecosystems that it depends on for success have the potential to create pathways to environmentally robust energy system.

Carbon storage and stabilization is probably the most direct and important quality for climate change mitigation efforts based on biochar. Every ton of biochar applied to the soil and that remains in the soil is equivalent to 0.61 to 0.80 tons of carbon (i.e. to 2.2 to 2.93 tons of $\mathrm{CO}_{2}$ ) sequestered [5]. It is a lower-risk strategy than other carbon sequestration options currently under discussion; carbon sequestering through afforestation has already been accepted as tradable 'carbon offsets' under the Kyoto Protocol (Smith et al. 2013). At a time when geo-engineering is attracting growing interest as a potential option for keeping global warming below $2^{\circ} \mathrm{C}$, carbon sequestration possibilities of biochar are seen as a promising route to climate mitigation.

\section{Opportunities and Risks}

Biochar systems are inherently complex, and the potential to address multiple challenges is contingent on new knowledge on the design of the biochar system into which it is integrated. One risk that must be mitigated is that of emissions of methane and nitrous oxide during inefficient pyrolysis; engineering the unit to capture and recirculate emissions should be possible. When considering the overall opportunities and risks of biochar systems, five main factors need to be considered: impacts on soil health and agricultural productivity; climate mitigation potential; environmental impacts; social impacts; and competing uses of biomass. If it is produced with the intent to be applied to soil as a means of improving soil productivity, biochar could result in increased crop yields from previously degraded soils. The provision of energy through biochar (green charcoal) could bring benefits at many scales and could potentially add to the energy mix. However, the success of such an initiative depends on production of green charcoal at scale, local "ownership" of energy strategies, 
and conducive regulatory frameworks. Pyrolysis systems that operate at different scales require different amounts and sources of biomass. Matters of biomass availability, affordability, and alternative uses need to be considered.

While academic interest on biochar is rapidly increasing, the availability of feedstock's has been strongly questioned on the grounds of sustainability, feasibility, and scalability [2]. A large scale biochar industry may lead to land use change due to demand for certain types of biomass (a risk minimized by using true wastes (otherwise unutilized available resources) and/or forest abd agricultural byproducts. Also, char dust and other small particulate matter arising from biochar production can become airborne with uncertain global warming impacts, but more definitive adverse impacts on human health. Many of these risks can be avoided through the application of appropriate standards and safeguards throughout the biochar production chain, which are currently being developed by a constantly growing community of practitioners supported by science. Potential emissions of toxins and inhalation of dust and small particulate matter can have adverse health consequences; only a system that controls emissions should be considered.

\section{Conclusion}

Irrespective of the potential benefits of biochar, realization of the benefit of biochar depends on whether and how we implement biochar production and end-use systems. This in turn requires a highly location-specific understanding of people and their needs, values, and expectations. Precisely which categories of biomass could be most appropriate for a biochar system are highly location and system specific. Pyrolysis systems that operate at different scales require different amounts and sources of biomass. Biomass availability, their types, affordability, and alternative uses need to be considered. Thus, the future of biochar as a solution to multiple large-scale social challenges depends heavily on the production pathway, the type of feedstock used, and the ultimate end-use for the biochar. The knowledge enterprise around biochar is multifaceted and needs interdisciplinary thinking and innovative approaches to generating the knowledge and quantifying impacts so that it has social value and amenable to policy proposals.

\section{References}

1. IPCC (2014) Summary for policymakers. In: Climate Change 2014: Impacts, Adaptation, and Vulnerability. Part A: Global and Sectoral Aspects. Contribution of Working Group II to the Fifth Assessment Report of the Intergovernmental Panel on Climate Change. In: Field CB, Barros VR, Dokken DJ, Mach KJ, Mastrandrea MD, (Eds.), Cambridge University Press, Cambridge, United Kingdom and New York, NY, USA, pp. 1-32.
2. Leach M, Fairhead J, Fraser J, Lehner E (2010) Biocharred Pathways to Sustainability? Triple Wins, Livelihoods and the Politics of Technological Promise, STEPS Working Paper 41, Brighton: STEPS Centre.

3. Lehmann J, Gaunt J, Rondon M (2006) Bio-Char Sequestration in Terrestrial Ecosystems-A Review. Mitigation and Adaptation Strategies for Global Change 11: 395-419.

4. Feng $Y, X u$ Y, Yu Y, Xie Z, Lin X (2012) Mechanisms of Biochar Decreasing Methane Emission from Chinese Paddy Soils. Soil Biology and Biochemistry 46: 80-88.

5. Weng Z, Van Zwieten L, Singh BP, Tavakkoli E, Joseph S, et al. (2017) Biochar built soil carbon over a decade by stabilizing rhizodeposits. Nature Climate Change 7(5): 371-376.

6. Rockstrom J, Steffen W, Noone K, Persson A, Chapin FS, et al. (2009) A safe operating space for humanity. Nature 461: 472-475.

7. Hammond J, Simon S, Miranda PM, Jason C, Sarah B, et al. (2013) Biochar field testing in the UK: outcomes and implications for use. Carbon Management 4(2): 159-170.

8. Verheijen F, Jeffery S, Bastos AC, Van Der Velde M, Diafas I (2010) Biochar Application to Soils-A Critical Scientific Review of Effects on Soil Properties. Processes and Functions, European Commission Joint Research Centre for scientific and Technical reports, pp. 51-68.

9. Scholz SM, Sembres T, Roberts K, Whitman T, Wilson K, et al. (2014) Biochar Systems for Smallholders in Developing Countries: Leveraging Current Knowledge and Exploring Future Potential for Climate-Smart Agriculture. World Bank Studies. Washington, DC: World Bank. License: Creative Commons Attribution CC BY 3.0 IGO.

10. Liu J, Schulz H, Brandl S, Miehtke H, Huwe B, et al. (2012) Short-term effect of biochar and compost on soil fertility and water status of a Dystric Cambisol in NE Germany under field conditions. Journal of Plant Nutrition and Soil Science 175(5): 698-707.

11. Uzoma KC, Inoue M, Andry H, Fujimaki H, Zahoor A, et al. (2011) Effect of cow manure biochar on maize productivity under sandy soil condition. Soil use and management 27(2): 205-212.

12. Asai H, Samson BK, Stephan HM, Songyikhangsuthor K, Homma K, et al. (2009) Biochar amendment techniques for upland rice production in Northern Laos: 1. Soil physical properties, leaf SPAD and grain yield. Field Crops Research 111(1-2): 81-84.

13. Solaiman ZM, Blackwell P, Abbott LK, Storer P (2010) Direct and residual effect of biochar application on mycorrhizal root colonisation, growth and nutrition of wheat. Soil Research 48(7): 546-554.

14. Blackwell P, Krull E, Butler G, Herbert A, Solaiman Z (2010) Effect of banded biochar on dryland wheat production and fertiliser use in south-western Australia: an agronomic and economic perspective. Soil Research 48(7): 531-545. 
Your next submission with Juniper Publishers will reach you the below assets

- Quality Editorial service

- Swift Peer Review

- Reprints availability

- E-prints Service

- Manuscript Podcast for convenient understanding

- Global attainment for your research

- Manuscript accessibility in different formats ( Pdf, E-pub, Full Text, Audio)

- Unceasing customer service

Track the below URL for one-step submission https://juniperpublishers.com/online-submission.php 